\title{
Glycine Uptake Regulates Hippocampal Network Activity via Glycine Receptor-Mediated Tonic Inhibition
}

\author{
Long-Hua Zhang ${ }^{1,2,4}$, Neng Gong ${ }^{1,2,4}, \mathrm{Da} \mathrm{Fei}^{1}$, Lin $\mathrm{Xu}^{3}$ and Tian-Le $\mathrm{Xu} \mathbf{u}^{*, 1}$ \\ 'Institute of Neuroscience and Key Laboratory of Neurobiology, Shanghai Institutes for Biological Sciences, Chinese Academy of Sciences, \\ Shanghai, China; ${ }^{2}$ School of Life Sciences, University of Science and Technology of China, Hefei, China; ${ }^{3}$ Laboratory of Learning and Memory, \\ Kunming Institute of Zoology, Chinese Academy of Sciences, Kunming, China
}

\begin{abstract}
Functional glycine receptors (GlyRs) are enriched in the hippocampus, but their role in hippocampal function remains unclear. Since the concentration of ambient glycine is determined by the presence of powerful glycine transporter (Gly T), we blocked the reuptake of glycine in hippocampal slices to examine the role of GlyRs. Antagonists of GlyT type I (GlyTI) but not that of GlyT type 2 (GlyT2) induced excitatory postsynaptic potential (EPSP)-spike depression, which was reversed by the specific GlyR antagonist strychnine. Moreover, endogenously elevating the glycine concentration with the GlyTI antagonists facilitated NMDA receptor-dependent longterm potentiation induction, and elicited a strychnine-sensitive chloride current. In addition, impairment of glial function with fluoroacetate blocked the effect of GlyTI antagonists on the EPSP-spike curve. Furthermore, pretreatment with sarcosine was effective in controlling pentylenetetrazol-induced seizures. These results indicate an essential role of GlyTs in fine-tuning tonic activation of GlyRs and suggest a potential role of GlyR-dependent EPSP-spike depression in hippocampal network stability.

Neuropsychopharmacology (2008) 33, 70I-7II; doi:I0.1038/sj.npp. I301449; published online 23 May 2007
\end{abstract}

Keywords: glycine receptor; glycine transporter; hippocampus; EPSP-spike coupling; tonic inhibition; glia

\section{INTRODUCTION}

Glycine is a major inhibitory neurotransmitter in the spinal cord and brain stem, acting on strychnine (STN)-sensitive glycine receptor (GlyR) chloride channels to induce neuronal inhibition (Legendre, 2001). Electrophysiological (Thio et al, 2003; Chattipakorn and McMahon, 2003), immunocytochemical (Becker et al, 1993), and in situ hybridization studies (Malosio et al, 1991) have shown that functional GlyRs are also present in many regions of developing and mature brain, including the hippocampus, where they are expressed by CA1 pyramidal cells and interneurons. Although no glycinergic synaptic transmission has been found in the hippocampus (Mody et al, 1994), accumulating evidence shows the presence of non-synaptic GlyRs containing at least $\alpha 2$ subunit (Chattipakorn and McMahon, 2002; Mori et al, 2002; Thio et al, 2003; Yoon et al, 1998). Thus, GlyRs are likely to have profound effects on cortical function, and may play a fundamental role in modulating hippocampal excitability.

At inhibitory synapses, the postsynaptic actions of glycine are terminated by the rapid reuptake mechanism, which is

\footnotetext{
*Correspondence: Dr T-L Xu, Institute of Neuroscience, Shanghai Institutes of Biological Sciences, Chinese Academy of Sciences, 320 Yue-yang Road, Shanghai 200031, China, Tel: +86 21 54921751, Fax: + 8621 54921735, E-mail: tlxu@ion.ac.cn

${ }^{4}$ These authors contributed equally to this work.

Received 21 December 2006; revised 19 March 2007; accepted II April 2007
}

mainly mediated by glycine transporters (GlyTs) (Gomeza et al, 2003). In the hippocampus, where rare GlyT type 2 (GlyT2) (Jursky and Nelson, 1995) but robust GlyT type 1 (GlyT1) (Zafra et al, 1995) is expressed and colocalized with $\mathrm{N}$-methyl-D-aspartate receptors (NMDAR) (Smith et al, 1992), the blockade of high-affinity GlyT1 modulates NMDAR-mediated responses and long-term potentiation (LTP) by increasing extracellular glycine levels (Martina et al, 2004; Kinney et al, 2003). Several other observations from rat prefrontal cortical neurons (Chen et al, 2003), spinal cord lamina X neurons (Bradaia et al, 2004), and hypoglossal motorneurons (Lim et al, 2004) also support a role of elevated glycine levels in NMDAR activity through GlyT1-dependent processes. However, recent reports demonstrate that the dominant endogenous co-agonist for NMDAR neurotoxicity is D-serine but not glycine (Shleper et al, 2005). Furthermore, high concentrations of glycine prime NMDAR internalization (Nong et al, 2003), which may lead to a concentration-dependent dual regulation of NMDAR-mediated responses. Additional studies report that GlyRs can affect GABAergic responses through crossinhibition between GlyRs and $\mathrm{GABA}_{\mathrm{A}}$ receptors $\left(\mathrm{GABA}_{\mathrm{A}} \mathrm{Rs}\right)$ ( $\mathrm{Li}$ and $\mathrm{Xu}, 2002 ; \mathrm{Li}$ et al, 2003). All these studies point to additional roles of glycine in the hippocampus beyond the potentiation of excitatory neurotransmission.

The excitatory postsynaptic potential (EPSP)-spike (E-S) potentiation is a phenomenon associated with the induction of LTP, which represents a larger population spike (PS) amplitude for a given EPSP size (Chavez-Noriega et al, 
1989), reflecting an increase in the ability of the EPSP to generate a spike. It is also a consequence of decreased inhibition within the hippocampal circuitry, since a loss of GABA-mediated inhibition can induce E-S potentiation (Chavez-Noriega et al, 1989). We hypothesized that, similar to GABA, elevated glycine acting through GlyRs could serve as an additional or alternative means of regulating the net balance between excitation and inhibition in the hippocampus. To test this hypothesis, we blocked the reuptake of glycine to study the effects of elevated glycine on E-S coupling as well as on LTP in hippocampal slices. We also examined the effect of a GlyT1 antagonist under conditions of abnormal excitability such as epilepsy. Our findings suggest that glial transporters play an essential role in fine-tuning the tonic activation of GlyRs, which in turn regulates hippocampal network activity and may further maintain network stability.

\section{MATERIALS AND METHODS}

The care and use of animals in these experiments followed the guidelines of, and the protocols were approved by, the Institutional Animals Care and Use Committee of the Institute of Neuroscience, Shanghai Institutes for Biological Sciences, Chinese Academy of Sciences.

\section{Hippocampal Slice Preparation and Solutions}

Slice preparation. Experiments were performed on $400 \mu \mathrm{m}$ transverse hippocampal slices from 14- to 17-day-old Sprague-Dawley rats. After decapitation, the brain was removed and placed in oxygenated $\left(95 \% \quad \mathrm{O}_{2} / 5 \% \mathrm{CO}_{2}\right)$ artificial cerebrospinal fluid (ACSF) at $4^{\circ} \mathrm{C}$. Slices were cut from the dorsal hippocampus with a vibratome (Leika VT $1000 \mathrm{~S})$ and maintained at room temperature $\left(23-25^{\circ} \mathrm{C}\right)$ in a holding chamber filled with oxygenated ACSF. In experiments where the $\mathrm{GABA}_{\mathrm{A}} \mathrm{R}$ antagonist bicuculline methiodide (BMI) was applied to the bath, the CA3 region of each slice was excised before recording to prevent epileptic discharges in the slice. After an equilibration period of at least $2 \mathrm{~h}$, a single slice was transferred to the recording chamber, where it was held between two nylon nets and continuously perfused with oxygenated $\operatorname{ACSF}\left(23-25^{\circ} \mathrm{C}\right)$ at a flow rate of $2.5-3 \mathrm{ml} / \mathrm{min}$.

Solutions. The ACSF for incubation and recording was composed of (in mM) $119 \mathrm{NaCl}, 2.5 \mathrm{KCl}, 1.3 \mathrm{MgSO}_{4}, 1.0$ $\mathrm{NaH}_{2} \mathrm{PO}_{4}, 26.2 \mathrm{NaHCO}_{3}, 2.5 \mathrm{CaCl}_{2}$, and 11 D-glucose, aerated with $95 \% \mathrm{O}_{2}$ and $5 \% \mathrm{CO}_{2}$ at a final $\mathrm{pH}$ of 7.4. The osmolarity of the ACSF was $289-295 \mathrm{mOsm} / \mathrm{l}$. The ionic composition of the internal solution for voltage-clamp recording was (in $\mathrm{mM}$ ) $120 \mathrm{KCl}, 10 \mathrm{HEPES}, 30 \mathrm{NaCl}, 0.5$ $\mathrm{CaCl}_{2}, 5 \mathrm{EGTA}$, and $1 \mathrm{MgCl}_{2}$, adjusted to $\mathrm{pH} 7.2$ with $\mathrm{KOH}$.

Drugs. All drugs and chemicals were purchased from Sigma (St Louis, MO). Concentrated stock solutions in distilled water or dimethyl sulfoxide (DMSO) were diluted to the appropriate concentration in ACSF immediately before use. Drugs were applied to the bath for at least $10 \mathrm{~min}$ to determine their effects on E-S coupling. To record tonic current, tetrotoxin (TTX, $0.3 \mu \mathrm{M}$ ) was added to the bath to reduce random baseline current fluctuations.

\section{Electrophysiological Recordings}

Field recordings. A bipolar platinum-iridium stimulating electrode was placed in the Schaffer collateral axons to elicit field population responses. Stimuli $(0.1 \mathrm{~ms}$ duration) of $0.05-3 \mathrm{~mA}$ were delivered at $0.5 \mathrm{~Hz}$ for baseline measurements. Microelectrodes were pulled from borosilicate glass (1.5 mm O.D., $1.17 \mathrm{~mm}$ I.D.) using an electrode puller (PC-830, Narishige). To elicit and assess E-S coupling, a recording microelectrode filled with ACSF (3-6 M 2 ) was placed extracellularly in the stratum pyramidale of CA1 to record PS and field EPSPs (fEPSP) (see Figure 1Aa). The E-S coupling curves were constructed by varying intensity of stimulation, while recording the resulting fEPSP slope and PS amplitude (see Figure 1Ba). To determine the effect of GlyT1 antagonists on LTP induction, a recording microelectrode was placed in stratum radiatum of CA1 to record fEPSPs. Theta-burst stimulation (TBS) was delivered as 4 trains of 4 pulses at $100 \mathrm{~Hz}$ separated by $200 \mathrm{~ms}$ and repeated twice at $20 \mathrm{~s}$ intervals.

Whole-cell recordings. Whole-cell recordings were also made from the CA1 region of hippocampal slices. CA1 pyramidal neurons were visually identified using an infrared differential interference contrast video microscope (BX51WI, Olympus) with a $40 \times$ water immersion objective. Under voltage-clamp conditions, all cells were held at $-70 \mathrm{mV}$. The access resistance was $<30 \mathrm{M} \Omega$, and results were discarded if it changed by more than $20 \%$.

\section{Behavioral Test}

Male Sprague-Dawley rats (200-300 g) were individually housed in wire cages and kept under a $12 \mathrm{~h}$ light/dark cycle. Rats were randomly assigned to one of two groups: saline group and sarcosine-treated group. Saline or sarcosine $(400 \mathrm{mg} / \mathrm{kg})$ was injected intraperitoneally $30 \mathrm{~min}$ before a single injection of pentylenetetrazol (PTZ, $50 \mathrm{mg} / \mathrm{kg}$ ) to induce seizures (Psarropoulou et al, 1994). Immediately after injection, seizure activity was monitored for $30 \mathrm{~min}$. The latency to the onset of seizures and their duration were recorded.

\section{Data Acquisition and Analysis}

Signals were amplified (Axoclamp 200B), digitized at $10 \mathrm{kHz}$ (Digidata $1320 \mathrm{~A} / \mathrm{D}$ converter), and analyzed off-line using the Clampfit program in PCLAMP 9.0 (all from Axon Instruments).

Definition of E-S curves. Extracellular E-S coupling was expressed as the ratio of PS amplitude to fEPSP initial slope. To obtain the data for the E-S curves, an ascending series of $10-20$ stimulus intensities $(0.05-3 \mathrm{~mA})$ was applied multiple times, covering a range of responses from subthreshold to maximal. An average of 3-10 traces was generated at each stimulus intensity. The E-S curves were constructed by plotting the normalized PS amplitude $v s$ the normalized fEPSP slope (maximal response in control saline was defined as 1) over the entire range of intensities sampled. The PS amplitude was calculated as the difference between the average of the two peak positivities and the peak negativity (see Figure 1Ba). Only those experiments having stable baselines and stable E-S curves over multiple trials were included in the analysis. 
A
a

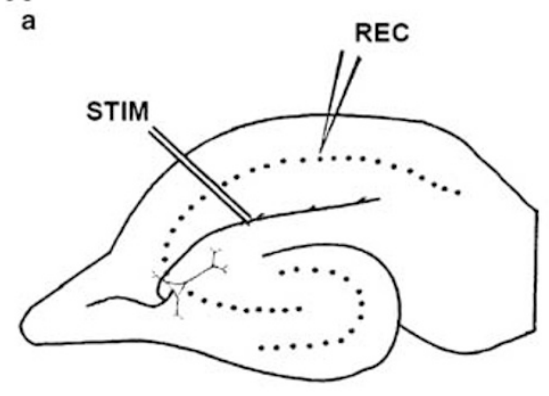

。

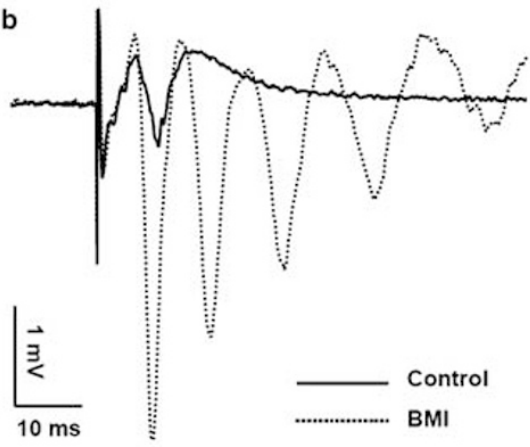

c

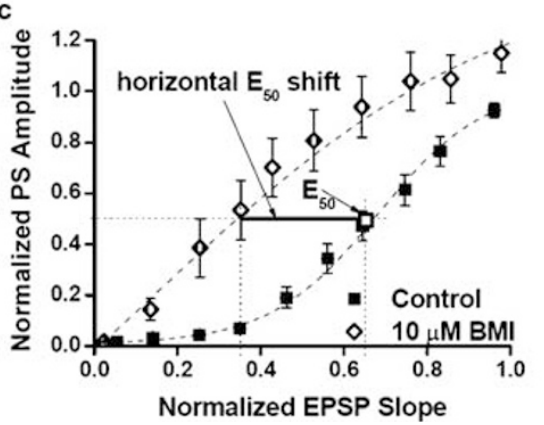

B
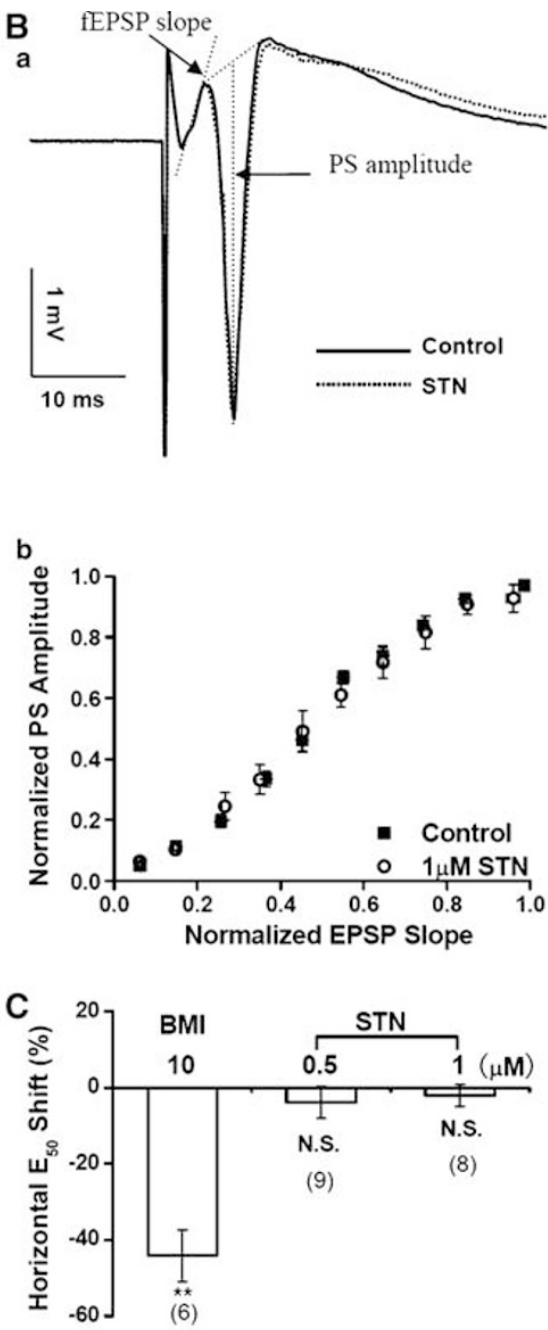

Figure I Effects of BMI and STN on extracellular fEPSP-spike (E-S) coupling in hippocampal slices. (A) BMI induced E-S potentiation. (a) Localization of stimulating and recording electrodes to record E-S coupling in the CAI region of the hippocampal slice. fEPSPs and PSs were recorded from the stratum pyramidale, the cell body layer. (b) Overlay of two sample voltage traces before and after application of BMI (IO $\mu$ M) at the same stimulus intensity. Each trace is an average of 3-5 sweeps. (c) The leftward shift of the E-S coupling curves induced by 10 min of BMl application $(n=6)$ compared with control level. The amplitude of PS normalized to maximal amplitude was plotted against the fEPSP slope normalized to maximal slope. The E-S curves were fitted with a sigmoidal equation and shown as dashed lines. The open square indicates the calculated $\mathrm{E}_{50}$ for the control curve. The solid line indicates the horizontal shift of $E_{50}$, which was calculated as the distance from the $E_{50}$ of the control curve to the horizontal $(\Delta x)$ intersection with the drug perfusion curve. (B) STN had no significant effect on E-S coupling. (a) Overlay of two sample traces before and after application of STN (I $\mu M$ ) at the same stimulus intensity. Each trace is an average of 3-5 sweeps. Dotted lines indicate fEPSP slope and PS amplitude measurements. (b) No difference was observed between the E-S curves before and after 10 min application of STN $(n=8)$. (C) Bar graph of averaged data expressed as percentage change in horizontal $E_{50}$ induced by application of antagonists, calculated as (horizontal $E_{50}$ shift/ $E_{50}($ control)) $\times 100 \%$. Bars represent the mean shift; error bars represent $S E M ; n$-values are indicated below each bar. Asterisks indicate a value significantly different from control groups before drug treatment, $p<0.0$ I, NS, not significant, one-sample $t$-test.

Statistics. The E-S curves were fitted with a sigmoidal equation using Origin 7.5 software. The $\mathrm{E}_{50}$ was defined as the value of fEPSP slope at which the PS amplitude was $50 \%$ of its maximal response. Horizontal $\mathrm{E}_{50}$ shift represented the percentage change of $\Delta x / x$, where $x$ was the $\mathrm{E}_{50}$ of the E-S curve before application of drugs and $\Delta x$ was calculated as the distance of the curve from the $\mathrm{E}_{50}$ before drug application to the horizontal intersection with the curve after application of drugs (see Figure 1Ac). This resembles $\mathrm{E}_{50}$ shift but is a more reliable and conservative measure when comparing two E-S curves that have different upper asymptotes. So, horizontal $\mathrm{E}_{50}$ shift was adopted as a standard measure in this study. Changes induced by drugs were expressed as percentage of the value before drug application, which was taken to be $100 \%$. Statistical analyses of the shifts used two-tailed, one-sample $t$-tests to determine significant differences from zero. For one-sample $t$-tests, degrees of freedom $(\mathrm{df})=n-1$, where $n$ was the number of cells. The mean tonic current was measured as follows. The baseline was calculated by generating all-point histograms of $10 \mathrm{~s}$ epochs at periods $\mathrm{a}, \mathrm{b}, \mathrm{c}$, and $\mathrm{d}$ (see Figure 5B), and a Gaussian distribution was fitted to the histogram at periods a, b, c, and d. The differences between the means of the fitted Gaussians at periods $a$ and $b$ and periods $b$ and $c$ were then calculated. Two changes in the baseline current were calculated between the three periods 
and compared in each cell using the paired $t$-test. Other data were analyzed using Student's paired or unpaired $t$-test for paired or group comparisons, respectively. Data were reported as mean \pm SEM.

\section{RESULTS}

\section{Effects of GlyR Agonist and Antagonist on E-S Coupling in Hippocampal CA1 Region}

We recorded extracellular responses as fEPSPs and PSs through a pipette placed in the cell body layer of CA1 (Figure $1 \mathrm{Aa}$ ). In the experiment with $\mathrm{BMI}$, the $\mathrm{CA} 3$ region was excised from the slice, and only the amplitude of the first PS was calculated (Figure 1Ab). Both fEPSP slope and PS amplitude increased dramatically after application of $10 \mu \mathrm{M}$ BMI. But this PS enhancement overwhelmed that of the fEPSP slope, leading to a leftward shift of the E-S curve (Figure 1Ac), which reflects decreased inhibition within the hippocampal network. The horizontal $\mathrm{E}_{50}$ shift (see Materials and Methods) induced by BMI was $-44.14 \pm 6.74 \%$ $(t=-6.6, \mathrm{df}=5, p<0.01$; Figure 1C; negative values reveal a left shift, while positive values show a right shift of the E-S curve). Meanwhile, TBS also induced a leftward shift of the E-S curve $(t=-3.9, \mathrm{df}=3, p<0.05)$, which is associated with the occurrence of LTP (Figure 4). Thus, our measurement of E-S coupling was feasible and could be used to examine the circuit properties of the hippocampus.

To determine whether activation of GlyRs has an effect similar to that of $\mathrm{GABA}_{\mathrm{A}} \mathrm{Rs}$ on E-S coupling, we tested the effect of STN, a selective antagonist of GlyRs. Unlike the robust effect of BMI, STN had little effect on either fEPSP slope or PS amplitude, leaving the E-S curve unchanged
(Figure $1 \mathrm{Bb})$. The horizontal $\mathrm{E}_{50}$ shift with STN $(0.5 \mu \mathrm{M})$ was $-3.88 \pm 4.24 \%(t=-0.9, \mathrm{df}=8, p>0.1$; Figure $1 \mathrm{C})$. Increasing STN concentration to $1 \mu \mathrm{M}$, the E-S curve was still unchanged (Figure $1 \mathrm{Ba}$ and $\mathrm{b}$ ), and the horizontal $\mathrm{E}_{50}$ shift was $-2.09 \pm 2.83 \%(t=-0.7, \mathrm{df}=7, p>0.1$; Figure $1 \mathrm{C})$.

We next asked whether exogenously applied GlyR agonists affect E-S coupling. To verify the efficiency of drug delivery, we first examined the effect of $\mathrm{GABA}_{\mathrm{A}} \mathrm{R}$ activation, which markedly affected E-S coupling (Figure $1 \mathrm{Ab}$ and $\mathrm{c}$ ). After bath application of $0.1 \mathrm{mM}$ GABA, the E-S curve shifted significantly to the right (Figure $2 \mathrm{a}$ ), with a horizontal $\mathrm{E}_{50}$ shift of $37.05 \pm 9.32 \%(t=4.0, \mathrm{df}=5, p<0.05$; Figure 2d), indicating that the drug was delivered efficiently. Then we tested the dose-response effects of glycine on the E-S curve and found that it was only effective at the highest concentration tested, $1 \mathrm{mM}(0.1 \mathrm{mM}, 5.12 \pm 3.69 \%, t=1.4$, $\mathrm{df}=13, \quad p>0.05 ; \quad 0.3 \mathrm{mM}, \quad 3.39 \pm 2.12 \%, \quad t=1.6, \quad \mathrm{df}=9$, $p>0.05 ; 1 \mathrm{mM}, 7.58 \pm 1.4 \%, t=5.8, \mathrm{df}=6, p<0.01$; Figure $2 \mathrm{~b}$ and $\mathrm{d}$ ). We also examined the effect of an endogenous GlyR agonist in the hippocampus, taurine $(1 \mathrm{mM}$, a concentration that does not affect $\mathrm{GABA}_{\mathrm{A}} \mathrm{Rs}$ ) (Mori et al, 2002; Wu and $\mathrm{Xu}, 2003$ ), to further confirm the involvement of GlyRs. A rightward shift of the E-S curve was evident after addition of taurine $(14.97 \pm 4.65 \%, t=3.3, \mathrm{df}=6$, $p<0.05$; Figure $2 \mathrm{c}$ and $\mathrm{d}$ ). Taken together, these results suggest that in intact slices, the concentration of endogenous agonist is not high enough to activate the GlyR so that plays a major role in neurotransmission or excitability, due probably to the presence of efficient glycine reuptake mechanisms in the hippocampus (Zafra et al, 1995). However, raising the agonist concentration overcame the clearance of glycine by GlyTs, thus unmasking its effect on E-S coupling.
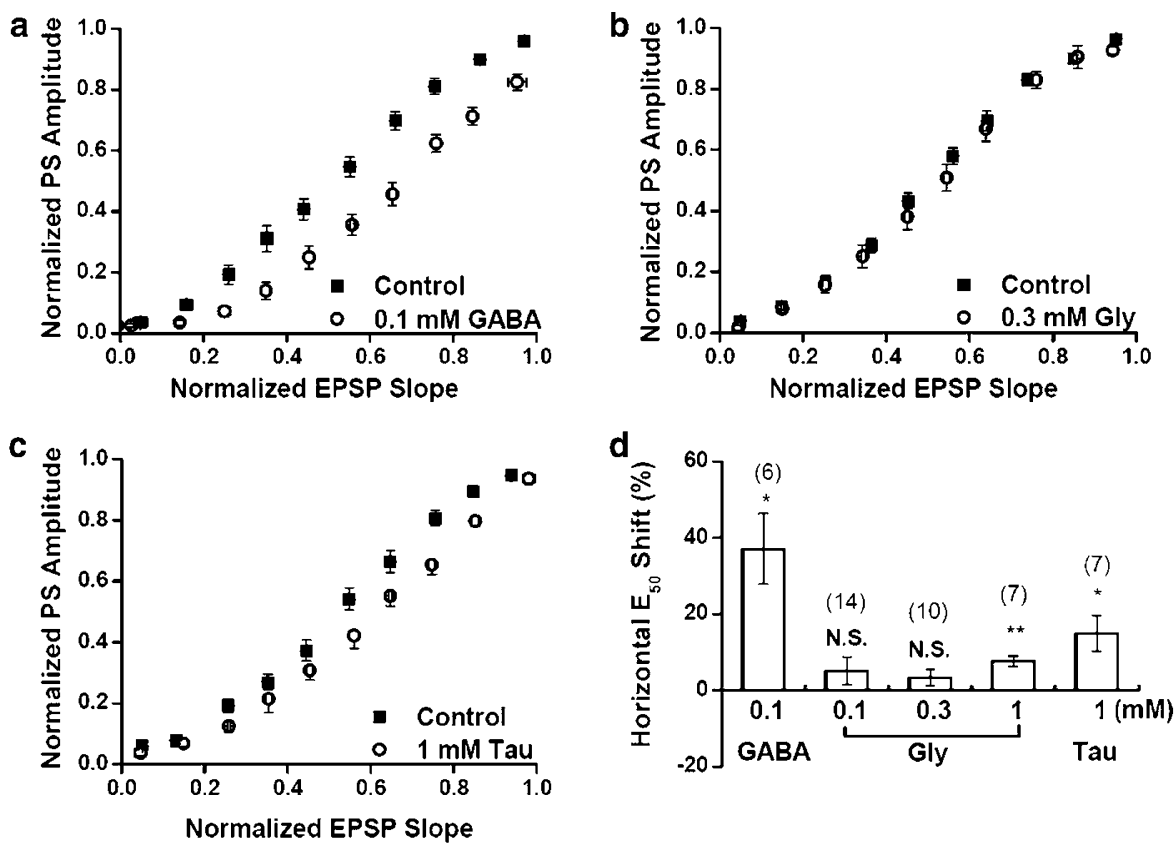

Figure 2 Effects of exogenous application of agonists on E-S coupling. (a) Bath application of GABA $(0.1 \mathrm{mM}, n=6)$ induced E-S depression. (b) Bath application of glycine (Gly, $0.1 \mathrm{mM}, n=14$ ) had no significant effect on E-S curves. (c) Bath application of taurine (Tau, I mM, n=7) induced a moderate E-S depression. (d) Bar graph of averaged data expressed as percentage change in horizontal $E_{50}$ induced by application of agonists. Bars represent the mean shift; error bars represent SEM; $n$-values are indicated above each bar. Asterisks indicate a value significantly different from control groups before drug treatment, $* p<0.05,{ }^{*} * x<0.01$, NS, not significant, one-sample t-test. 
GlyT1, but not GlyT2 Antagonists Induced STN-Sensitive E-S Depression

The difference in half-maximal concentrations of glycine responses in hippocampus between single neuron and slice preparations suggests the existence of powerful reuptake mechanisms in slices (Chattipakorn and McMahon, 2002). To look for direct evidence of a role of GlyTs in tuning tonic activation of GlyRs in hippocampus, we studied the effect of sarcosine, a specific GlyT1 antagonist, on E-S coupling. As expected, application of sarcosine $(0.5 \mathrm{mM})$ markedly shifted the E-S curve to the right (Figure 3a) without affecting the intrinsic membrane excitability (data not shown). The horizontal $\mathrm{E}_{50}$ shift was $13.94 \pm 2.76 \%(t=5$, $\mathrm{df}=24, p<0.001$; Figure $3 \mathrm{c})$. When STN $(1 \mu \mathrm{M})$ was applied to sarcosine-treated slices, E-S potentiation was consistently observed, and the horizontal $\mathrm{E}_{50}$ shift induced by STN was $-13.91 \pm 2.76 \%(t=-5, \mathrm{df}=8, p<0.01$ compared with the sarcosine group; Figure $3 \mathrm{~d})$. Thus, STN $(1 \mu \mathrm{M})$ restored the E-S curve to the control level (Figure 3a). A lower concentration of STN $(0.5 \mu \mathrm{M})$ had a similar effect on the E-S curve in the presence of sarcosine, and the horizontal $\mathrm{E}_{50}$ shift was $-12.66 \pm 2.11 \% \quad(t=-6, \mathrm{df}=7, \quad p<0.001$ compared with the sarcosine group; Figure 3d). These results indicate that blockade of GlyT1 unmasks the role of GlyRs in neuronal network activity.

To ensure that the effect of sarcosine on E-S coupling resulted from the blockade of GlyT1, another GlyT1 antagonist, $N$ [3-(4'-fluorophenil)-3-(4'-phenilphenoxy) propyl] sarcosine (NFPS), was applied. Similar to sarcosine, NFPS $(1 \mu \mathrm{M})$ shifted the E-S curve to the right $(15.97 \pm 6.90 \%, t=2.3$, $\mathrm{df}=10, p<0.05$; Figure $3 \mathrm{~b}$ and $\mathrm{c}$ ), and this was reversed by subsequent application of STN $(1 \mu \mathrm{M},-15.65 \pm 4.13 \%$, $t=-3.8, \mathrm{df}=8, p<0.01$ compared with the NFPS group; Figure $3 \mathrm{~b}$ and d). In view of the sparse distribution of GlyT2 in the hippocampus (Zafra et al, 1995), the effects of a GlyT2 antagonist, $O$-[(2-benzyloxyphenyl-3-flurophenyl)methyl]-Lserine (ALX-1393), was also tested. Unlike GlyT1 antagonists, ALX-1393 $(1 \mu \mathrm{M})$ did not shift the E-S curve $(-0.32 \pm 2.00 \%$, $t=-0.16, \mathrm{df}=5, p>0.1$; Figure 3c), indicating that GlyT2 blockade had no effect on GlyRs or neuronal excitability.

Since NFPS and ALX-1393 were dissolved in DMSO, the same concentration of DMSO was added to the bath to exclude its possible influence, and it had no effect on E-S coupling (3.63 $\pm 1.94 \%, t=-1.9, \mathrm{df}=6, p>0.1$; Figure $3 c)$. Application of STN also had no significant effect on E-S
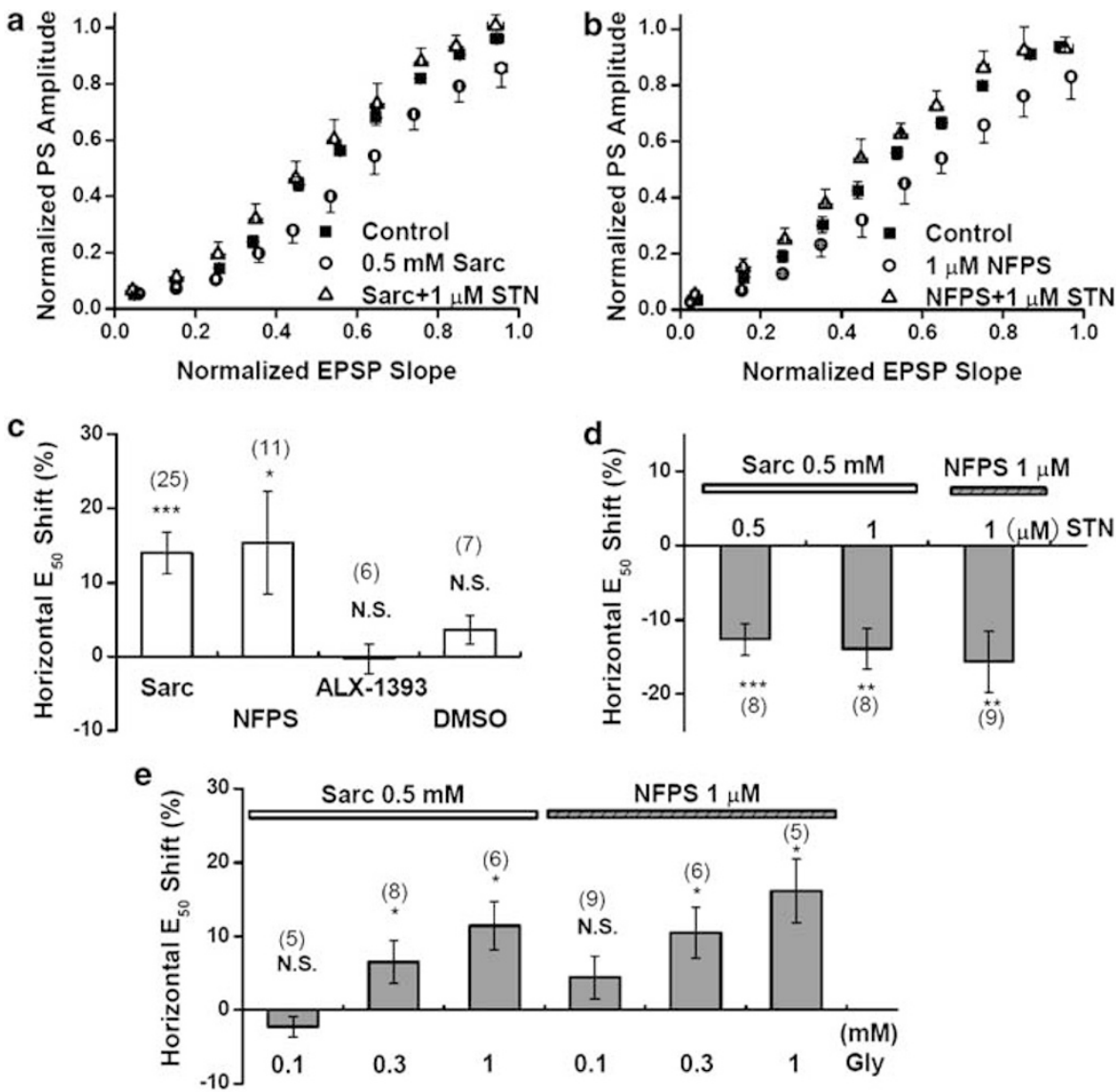

Figure 3 Blockade of GlyTI unmasked the effect of GlyRs on E-S coupling. (a) STN shifted the E-S curve to the left after blockade of Gly I by sarcosine (Sarc). After $10 \mathrm{~min}$ of Sarc $(0.5 \mathrm{mM})$ application, the E-S curve shifted to the right of the control curve. Subsequent application of STN (I $\mu \mathrm{M})$ for IO min reversed the shift. (b) STN shifted the E-S curve to the left after blockade of GlyTI by NFPS (I $\mu \mathrm{M})$. (c) Bar graph of averaged data expressed as percentage change in horizontal $\mathrm{E}_{50}$ induced by Sarc $(0.5 \mathrm{mM})$, NFPS (I $\left.\mu \mathrm{M}\right)$, ALX-1393 (I $\left.\mu \mathrm{M}\right)$, and DMSO, compared with control E-S curve. (d) Bar graph of averaged data expressed as percentage change in horizontal $E_{50}$ induced by STN, compared with E-S curve of Sarc or NFPS. (e) Bar graph of averaged data expressed as percentage change in horizontal $E_{50}$ induced by different concentration of Gly, compared with E-S curve of Sarc or NFPS without Gly. Bars represent the mean shift; error bars represent SEM; $n$ values are indicated above (c), (e) or below (d) each bar. Asterisks indicate a significant difference before and after drug treatment, $* p<0.05, * * 2<0.0$ I, **** $p<0.00$ I, NS, not significant, one-sample $t$-test. For ( $d$ and e), horizontal bars indicate the presence of Sarc $(0.5 \mathrm{mM})$ or NFPS (I $\mu \mathrm{M})$. 
coupling in the presence of DMSO, the horizontal $\mathrm{E}_{50}$ shift being $-2.39 \pm 2.57 \%(t=-0.9, \mathrm{df}=4, p>0.05)$ compared with the E-S curve for DMSO, indicating that the effect of STN was also independent of solvent. These results indicate that the effects of both sarcosine and NFPS on E-S coupling result from the blockade of GlyT1.

We then asked whether exogenous glycine further affects the E-S curve after GlyT1 blockade. When glycine was applied to the bath in the presence of sarcosine $(0.5 \mathrm{mM})$, no further shift of the E-S curve was observed $(0.1 \mathrm{mM},-2.27 \pm 1.42 \%$, $t=-1.6, \mathrm{df}=4, p>0.1$ compared with the sarcosine group; Figure $3 \mathrm{e}$ ) until the glycine concentration was raised to $0.3 \mathrm{mM}(6.50 \pm 2.90 \%, t=2.4, \mathrm{df}=7, p<0.05$ compared with the sarcosine group; Figure $3 \mathrm{e})$ and $1 \mathrm{mM}(11.43 \pm 3.28 \%$, $t=3.8, \mathrm{df}=5, p<0.05$ compared with the sarcosine group; Figure 3e). Similarly, in the presence of NFPS $(1 \mu \mathrm{M})$, glycine induced further E-S shift at concentrations higher than $0.3 \mathrm{mM}(0.1 \mathrm{mM}, 4.41 \pm 2.92 \%, t=1.5, \mathrm{df}=8, p>0.1$ compared with the NFPS group; $0.3 \mathrm{mM}, 10.48 \pm 3.42 \%, t=3.1$, $\mathrm{df}=5, p<0.05$ compared with the NFPS group; $1 \mathrm{mM}$, $16.13 \pm 4.31 \%, t=3.7, \mathrm{df}=4, p<0.05$ compared with the NFPS group; Figure 3e). Thus, a lower concentration of glycine, which failed to affect E-S coupling in native slices (Figure 2d), became effective in sarcosine- and NFPS-treated slices, favoring the idea of a functional role of GlyTs in tuning tonic activation of GlyRs in the hippocampus.

\section{GlyT1 Antagonists Facilitated LTP Induction}

Elevation of extracellular glycine is known to facilitate LTP induction in several brain regions including the hippocampus (Martina et al, 2004; Kinney et al, 2003). To determine whether GlyT1 antagonists elevated extracellular glycine levels under our experimental conditions, we examined their effect on synaptic plasticity in hippocampal slices. An electrode was placed in the stratum radiatum of CA1 to record fEPSPs. After $10 \mathrm{~min}$ of recording, a stable baseline fEPSP, TBS increased the fEPSP slope to about $1.34 \pm 0.04$ $(n=5, p<0.01)$ of baseline, lasting for more than $40 \mathrm{~min}$ (Figure 4). This LTP was NMDAR dependent, since it was prevented by D-AP5 $(20 \mu \mathrm{M} ; 0.94 \pm 0.03$ of baseline, $n=5$, $p>0.05$; Figure $4 \mathrm{a})$. In the presence of sarcosine $(0.5 \mathrm{mM})$, TBS induced a larger increase of the fEPSP slope to about $1.52 \pm 0.05$ of baseline ( $n=5, p<0.01$; Figure $4 \mathrm{a})$. Similarly, another GlyT1 antagonist, NFPS $(1 \mu \mathrm{M})$ also increased TBSinduced LTP to about $1.55 \pm 0.03$ of baseline $(n=6, p<0.01$; Figure $4 \mathrm{~b}$ ). This result supports the idea that GlyT1 antagonists facilitate the induction of NMDAR-dependent LTP, which results from the accumulation of extracellular glycine via inhibiting glycine reuptake and the subsequent augmentation of NMDAR responses by acting on the glycine binding site of NMDARs.

\section{Sarcosine Induced STN-Sensitive Tonic Currents}

The findings described above indicate a clear involvement of hippocampal GlyRs in regulating E-S coupling. Since no functional glycinergic neurotransmission has been demonstrated in the hippocampus, we hypothesized that sarcosine could induce a tonic GlyR current via inhibiting glycine reuptake as evidenced by its role in facilitating LTP induction (Figure 4). We thus recorded sarcosine-induced whole-cell current from pyramidal neurons in CA1, with TTX $(0.3 \mu \mathrm{M})$ in the bath to reduce random baseline current fluctuations. At a holding potential of $-70 \mathrm{mV}$, the chloride current was magnified through the high chloride intracellular solution (see Materials and Methods). Bath application of sarcosine $(0.5 \mathrm{mM})$ induced a persistent inward current and an increase in membrane current noise, while pretreatment with STN $(1 \mu \mathrm{M})$ but not D-AP5 $(20 \mu \mathrm{M})$ blocked the effect of sarcosine on holding current, favoring an involvement of GlyRs (Figure 5A). Consistently, in the presence of sarcosine, application of STN resulted in an outward shift in the baseline current (Figure 5B). The value of period c-b $(6.6 \pm 1.1 \mathrm{pA}, n=6)$ was significantly larger $(p<0.01$, paired $t$-test $)$ than period $\mathrm{b}-\mathrm{a}(-1.5 \pm 0.7 \mathrm{pA}$,
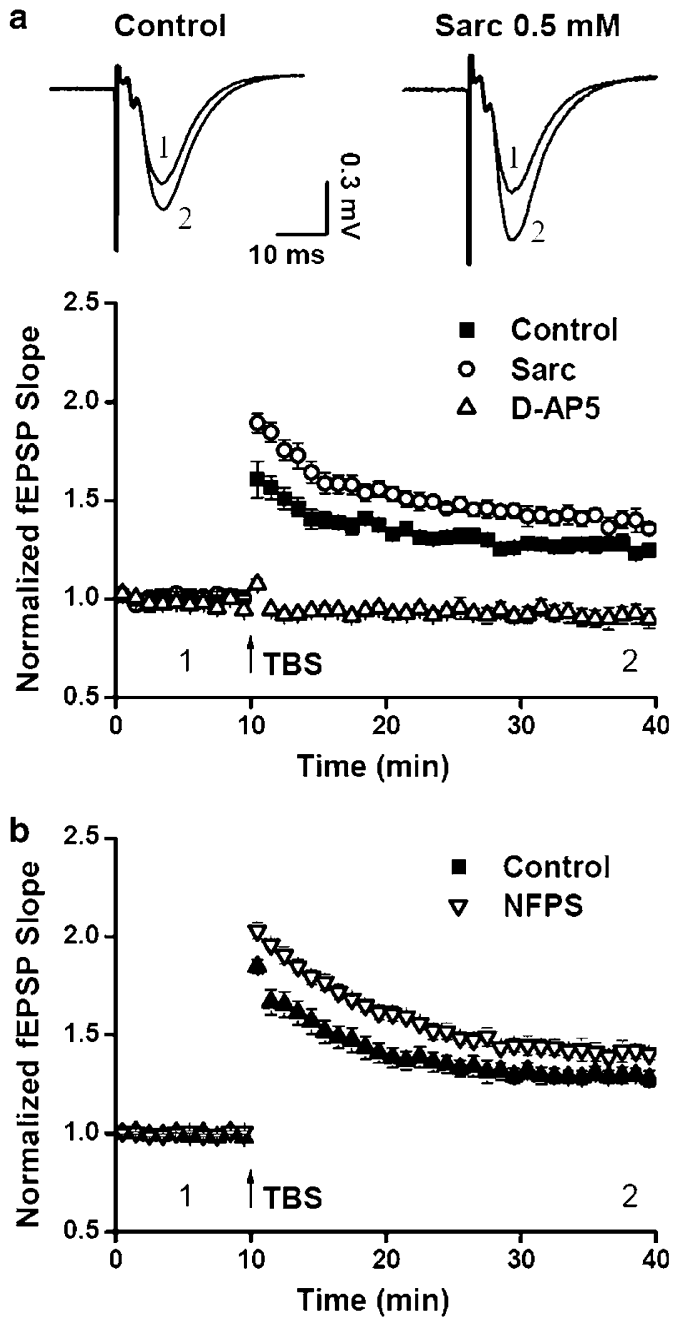

Figure 4 Blockade of GlyTI facilitated NMDAR-dependent LTP induction. (a) Upper: Examples of fEPSPs (each trace is an average of 10 sweeps) recorded in control (absence of drug) and in the presence of Sarc $(0.5 \mathrm{mM})$, as indicated below ( 1 and 2). Lower: TBS (4 trains of 4 pulses at $100 \mathrm{~Hz}$ separated by $200 \mathrm{~ms}$ and repeated twice at $20 \mathrm{~s}$ intervals) was employed to induce LTP. This protocol induced a long-lasting increase of the fEPSP slope (control; $1.34 \pm 0.04$ of baseline, $n=5, p<0.01$ I. Student's t-test; Sarc; $1.52+0.05$ of baseline, $n=5, p<0.01$, Student's $t$-test). The LTP induced by this protocol was prevented by the application of D-AP5 ( $20 \mu \mathrm{M} ; 0.94 \pm 0.03$ of baseline, $n=5, p>0.05$, Student's $t$-test). (b) NFPS also facilitated TBS-induced LTP (control; $1.36 \pm 0.04$ of baseline, $n=6$, $p<0.0$ I, Student's t-test; NFPS; $1.55 \pm 0.03$ of baseline, $n=6, p<0.0$ I, Student's t-test). 
$n=6$ ), showing that the change in baseline was indeed due to the effect of the antagonist (Figure $5 \mathrm{Ca}-\mathrm{Cd}$ and $\mathrm{D}$ ). When the concentration of sarcosine was raised to $2 \mathrm{mM}$, STN induced a larger change in holding current (data not shown). However, STN alone failed to reduce the amplitude of the holding current (Figure 5B) and the values of period $\mathrm{c}-\mathrm{b}(-0.3 \pm 1.3 \mathrm{pA}, n=9)$ and period $\mathrm{b}-\mathrm{a}(0.3 \pm 1.0 \mathrm{pA}$, $n=9$ ) were not significantly different ( $p>0.05$; Figure $5 \mathrm{D})$. In addition, bath application of glycine $(10 \mu \mathrm{M})$ induced a small STN-sensitive inward current, which rapidly returned to baseline $(n=2)$. These results further confirm that an accumulation of extracellular glycine induced by GlyT1 blockade is required for tonic activation of GlyRs.

\section{Impairment of Astrocytes Abolished the Effect of GlyT1 Antagonists on E-S Coupling}

In view of the lack of GlyT2 expression in hippocampal neurons but abundant distribution of GlyT1 in hippocampal astrocytes (Zafra et al, 1995), we hypothesized that astrocyte-derived glycine is responsible for the sarcosineinduced E-S depression. To test this possibility, we used a glia-specific metabolic inhibitor, fluoroacetate (FAC), to interfere with glial cell functions (Figure 6). Before field potential recording, hippocampal slices were incubated in FAC $(3 \mathrm{mM})$ for $2-4 \mathrm{~h}$, conditions that permit FAC to suppress glial function effectively while exerting little effect on neurons (Swanson and Graham, 1994). Under these conditions, application of sarcosine $(0.5 \mathrm{mM})$ had little effect on the E-S curve, and the horizontal $\mathrm{E}_{50}$ shift induced by sarcosine was $5.75 \pm 5.68 \% \quad(t=0.6, \mathrm{df}=4, p>0.05$ compared with the FAC-treated group; Figure 6Aa and B). Similarly, application of NFPS $(1 \mu \mathrm{M})$ showed no significant shift of the E-S curve $(2.7 \pm 1.0 \%, t=-1.9, \mathrm{df}=8, p>0.05$ compared with the FAC-treated group; Figure $6 \mathrm{Ab}$ and $\mathrm{B}$ ). These results indicate that glial cells are essential for GlyT1 blockade-induced STN-sensitive E-S depression.

In the presence of both FAC and GlyT1 antagonists (sarcosine or NFPS), subsequent application of STN $(1 \mu \mathrm{M})$ did not affect the E-S curve (Figure 6A and $\mathrm{C}$ ), and the horizontal $\mathrm{E}_{50}$ shift induced by STN was $-0.2 \pm 2.61 \%$ in the presence of sarcosine $(t=-0.1, \mathrm{df}=4, p>0.1$; Figure $6 \mathrm{C})$ and $-5.74 \pm 2.49 \%$ in the presence of NFPS $(t=-2.3$, $\mathrm{df}=7, p>0.05$; Figure $6 \mathrm{C}$ ) compared with the E-S curve before STN application. These results implied that glial cells were also essential for the endogenous accumulation of
A

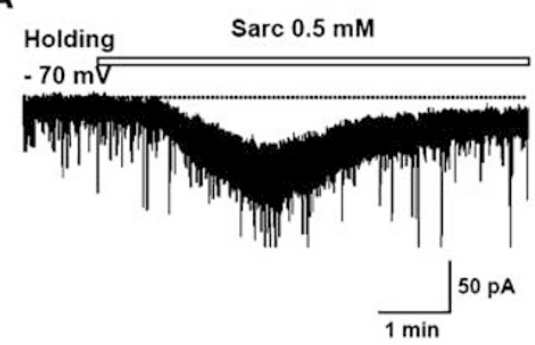

STN $1 \mu \mathrm{M}$

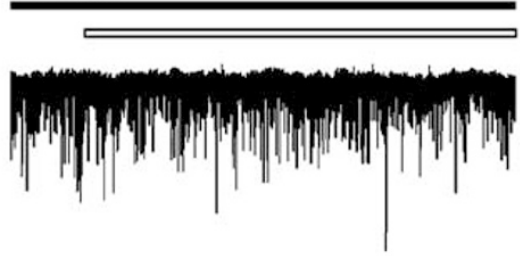

D-AP5

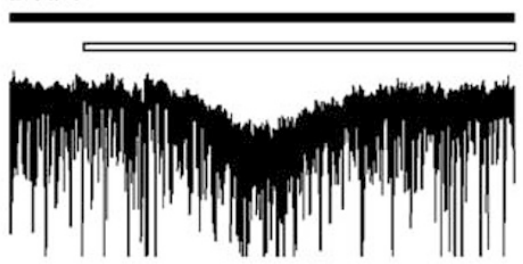

B

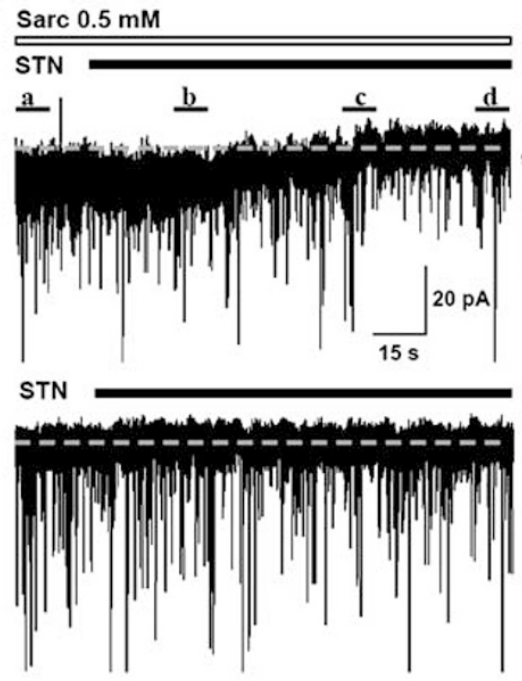

D

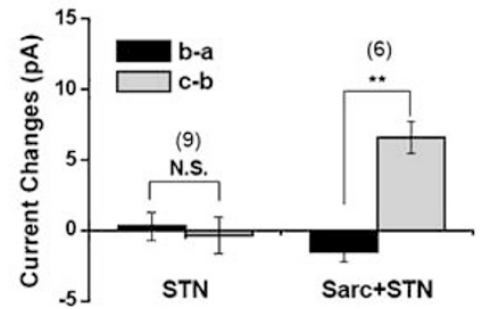

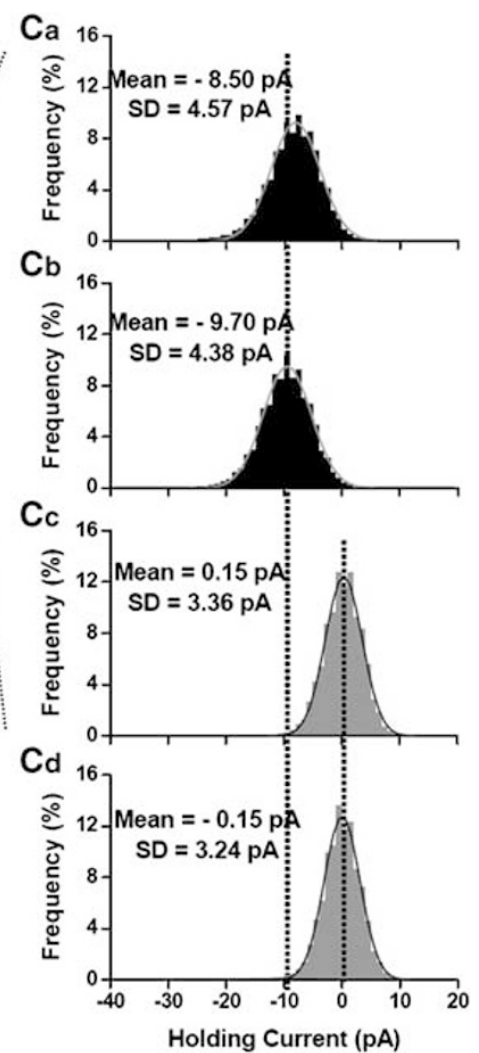

Figure 5 Blockade of GlyTI induced tonic activation of GlyRs. (A) Upper: whole-cell voltage-clamp recording showing the effect of Sarc (0.5 mM) on baseline current. Sarc induced an increase in membrane current noise accompanied by an inward current in a CAI pyramidal neuron (observed in 8 of I 4 cells). The dotted line indicates the baseline current before Sarc application. Middle: STN (I $\mu$ M) blocked the inward current induced by Sarc ( $n=6)$. Lower: D-AP5 $(20 \mu \mathrm{M})$ could not block the inward current induced by Sarc $(n=5)$. (B) Upper: Application of STN (I $\mu$ M) decreased membrane current noise and induced an outward current in the presence of Sarc (0.5 mM, observed in 6 of I I cells). Inset illustrates the average baseline values between 0 and I $0 \mathrm{~s}$ (a), 50 and $60 \mathrm{~s}(\mathrm{~b}), 100$ and $110 \mathrm{~s}$ (c), and 140 and $150 \mathrm{~s}$ (d). The baseline level was set to zero during the recording periods c and d, shown as the dashed line. Lower: Application of STN ( $\mid \mu M)$ alone did not affect holding current $(n=9)$. For (A and B), recordings were performed in the presence of $0.3 \mu \mathrm{M}$ TTX. Horizontal bars indicate the time course of perfusion of Sarc, STN, or D-AP5. The holding potential was $-70 \mathrm{mV}$. (Ca-Cd) All-point histograms of I0 s traces at time points a, b, c, and d as indicated in B (upper). The histograms were fitted with single Gaussians, and the means and standard deviation (SD) were determined. (D) The histograms represent the differences between the means of the fitted Gaussians at periods a and $b$ and periods $b$ and $c$. Asterisks indicate significant differences between $b-a$ and $c-b$ groups, $* * * 0.01$, NS, not significant, paired t-test. Error bars indicate SEM. 
glycine. We also determined whether the NMDARs played a role in the STN-induced shift of the E-S curve after blockade of GlyT1. In the presence of both sarcosine and the NMDA/glycine binding site inhibitor, 7-chlorokynurenic acid $(10 \mu \mathrm{M})$, STN still shifted the E-S curve to the left $(-11.03 \pm 3.1 \% . t=-3.6, \mathrm{df}=7, p<0.01$; Figure $6 \mathrm{C}) \mathrm{com}-$ pared with the E-S curve before STN application. This result together with the inability of D-AP5 in preventing sarcosine-induced tonic current (Figure 5A) supports the notion that NMDARs play little roles but activation of GlyRs is required for GlyT1 antagonists-induced regulation of hippocampal network activity.

\section{Sarcosine Inhibited PTZ-Induced Seizures}

Since sarcosine can induce E-S depression, which represents the downregulation of network activity, we wondered whether the application of sarcosine in vivo was effective in preventing abnormal excitability. The PTZ-induced seizure provides an ideal model of hyper-excitability to explore the anticonvulsant effect of sarcosine. We found that intraperitoneal injection of sarcosine at a dosage of $400 \mathrm{mg} / \mathrm{kg} 30 \mathrm{~min}$ before PTZ $(50 \mathrm{mg} / \mathrm{kg})$ treatment inhibited the PTZ-induced seizures. The latency to the onset of seizures was increased $(n=8, p<0.01$; Figure $7 a)$ and the duration of seizures was decreased $(n=8, p<0.05$; Figure 7b) by sarcosine. These results showed that sarcosine was anticonvulsant, which may reflect its role of inducing E-S depression and thus preventing hyper-excitability.

\section{DISCUSSION}

Homeostatic regulation of neural activity is a process that avoids the extremes of complete quiescence or excessive action potential firing. Several mechanisms, such as the densities of voltage-gated ion channels and postsynaptic receptors, presynaptic transmitter release or reuptake, global regulation of synaptic strengths throughout a neuron, and the number of functional synapses have been shown to contribute to homeostasis (Turrigiano and Nelson, 2004). Adding to the growing knowledge of this type of regulation, we used GlyT1 antagonists to demonstrate a GlyRdependent decrease in E-S coupling accompanied by an NMDAR-dependent increase in the magnitude of LTP. This change is consistent with an STN-sensitive tonic current that leads to a decrease in network excitability since E-S coupling reflects the ability of an EPSP with a fixed slope to elicit spikes. Our data also show that the GlyT1 antagonistinduced E-S depression was independent of intrinsic neuronal excitability, occurring when all excitatory and inhibitory neurotransmissions were blocked. Therefore, the GlyRs in the hippocampus are probably an autonomous homeostatic effector for controlling network excitability.

\section{Glycine Accumulation Reduces Overall Excitability}

Glycine can act on both GlyRs (Legendre, 2001) and NMDARs (Thomson et al, 1989) and regulate both inhibitory and excitatory neurotransmission. In the central nervous system, the concentration of glycine is tightly regulated by GlyTs (Gomeza et al, 2003). Here, we demonstrated that GlyT1 antagonist-induced blockade of GlyT1 increased the magnitude of NMDAR-dependent LTP induction (Figure 4), which is consistent with reports from several other groups that glycine accumulation facilitates the magnitude of LTP (Martina et al, 2004; Kinney et al, 2003). The LTP induction is usually accompanied by E-S
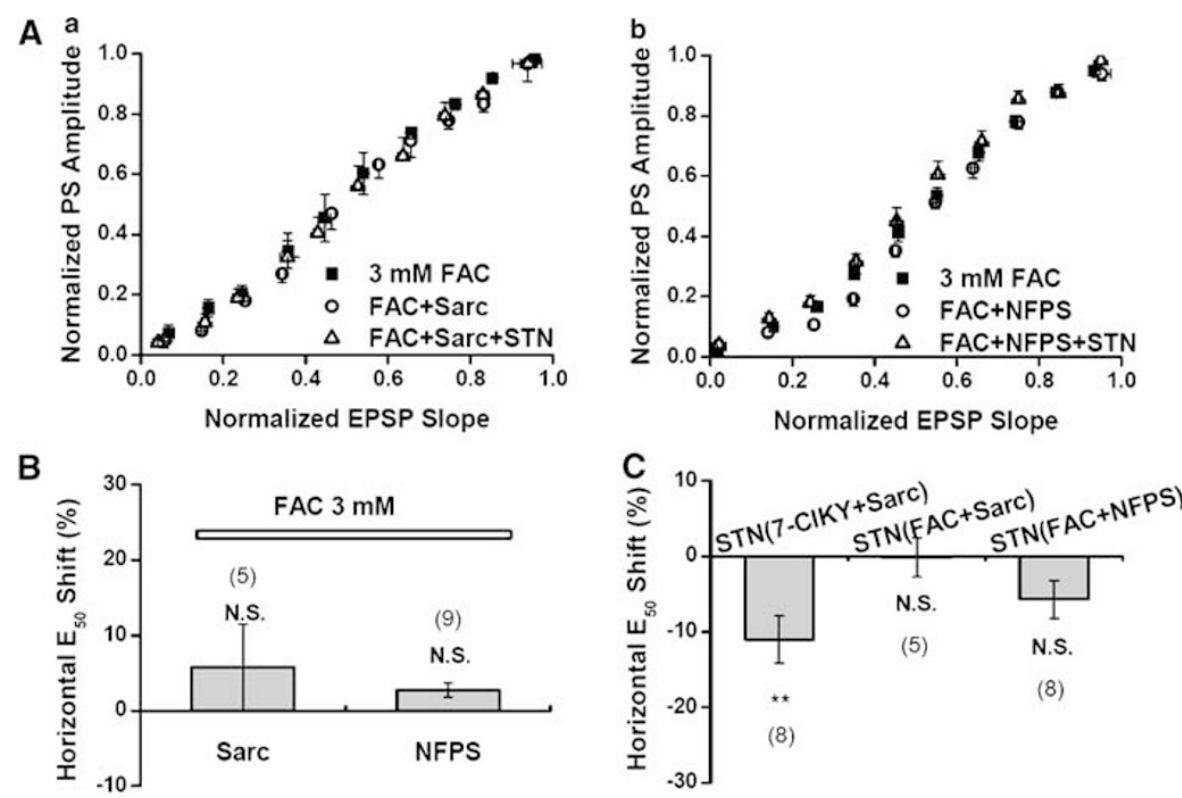

Figure 6 Involvement of glial cells in the effect of GlyTI antagonists and STN on E-S coupling. (A) Pretreatment with FAC (3 mM) for more than $2 \mathrm{~h}$ blocked the effect of GlyTI antagonists (Sarc, $0.5 \mathrm{mM}$; NFPS, I $\mu \mathrm{M}$ ) and STN (I $\mu \mathrm{M}$ ) on E-S coupling. (B) Bar graph of averaged data expressed as percentage change in horizontal $E_{50}$ induced by Sarc $(0.5 \mathrm{mM})$ and NFPS $(\mathrm{I} \mu \mathrm{M})$, compared with the E-S curve of the FAC alone. (C) Bar graph of averaged data expressed as percentage change in horizontal $E_{50}$ induced by STN $(I \mu M)$, compared with the E-S curve before STN perfusion. Bars represent the mean shift; error bars represent SEM; $n$-values are indicated above (B) or below (C) each bar. Asterisks indicate a significant difference before and after drug treatment, $* * * 0.0$ I, NS, not significant, one-sample $t$-test. For (B), horizontal bar indicates the presence of FAC (3 mM). For (C), pretreatment conditions are indicated in parentheses. 7-CIKY, 7-chlorokynurenic acid. 


\section{a}

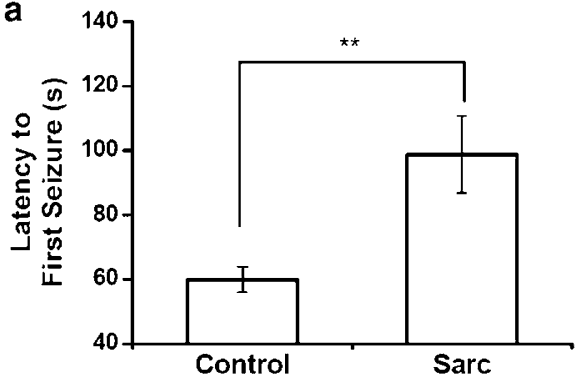

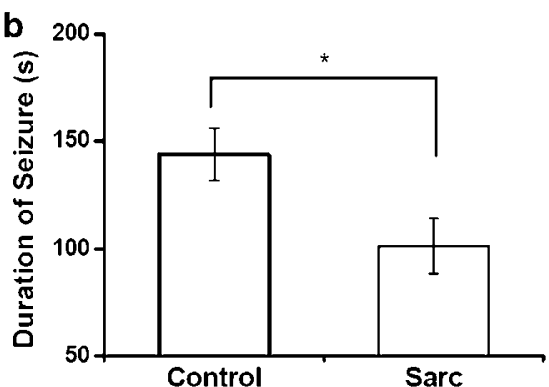

Figure 7 Latencies and durations of PTZ-induced seizures. (a) Latency (sec) to the onset of the first PTZ (50 mg/kg)-induced seizure for animals pretreated with saline (control) or Sarc $(400 \mathrm{mg} / \mathrm{kg}$ ). (b) The duration (sec) of PTZ-induced seizures in animals pretreated with saline (control) and Sarc. $n=8$ in each experimental group. Asterisks indicate a significant difference between two groups, * $p<0.05$, *** $p<0.0$ I, Student's t-test. Error bars indicate SEM.

potentiation (Bliss and Lomo, 1973), which leads to increased network activity. A previous study demonstrates that LTP of EPSPs is accompanied by LTD of GABAergic inhibitory postsynaptic potentials (Lu et al, 2000), which causes E-S potentiation (Staff and Spruston, 2003). Consistent with this observation, we found that $\mathrm{GABA}_{\mathrm{A}} \mathrm{R}$ blockade induced E-S potentiation (Figure $1 \mathrm{Ab}$ and $\mathrm{C}$ ). Therefore the main GABAergic inhibitory system may not participate in the homeostatic regulation of network activity following LTP. To avoid runaway excitation after LTP induction, other homeostatic mechanisms may be necessary for maintaining network stability.

Within the hippocampus, D-serine, but not glycine, is the dominant endogenous co-agonist for NMDARs (Shleper et al, 2005), so the accumulation of glycine probably has other roles beyond the potentiation of NMDAR-mediated responses. As discussed above, unlike D-serine, glycine can act on inhibitory GlyRs. It has been reported that the activation of GlyRs suppresses hyper-excitability in the hippocampus (Chattipakorn and McMahon, 2003). Following extracellular accumulation under certain conditions, glycine might regulate network activity via GlyR-mediated tonic inhibition. Indeed, we found that endogenous accumulation of glycine by GlyT1 antagonists induced an STN-sensitive tonic current in CA1 pyramidal neurons (Figure 5). The reported existence of GlyRs containing homomeric $\alpha 2$ subunits in the hippocampus (Chattipakorn and McMahon, 2002; Mori et al, 2002; Thio et al, 2003; Yoon et al, 1998) may underlie this tonic current. In general, functional consequences of the tonic inhibition are not well understood. The present results provide one of its possible roles in network activity, since GlyT1 antagonists also induced E-S depression (Figure 3c). The ability of STN to restore E-S curve after GlyT1 antagonist application (Figure 3d), even in the presence of the antagonist of NMDA/glycine binding site (Figure 6C), indicates the involvement of GlyRs but not NMDARs in the effect of GlyT1 antagonists on E-S coupling. Since E-S coupling is a mechanism underlying neuronal input-output functions (Chavez-Noriega et al, 1989), these results suggest that activation of GlyRs in the hippocampus could provide an inhibitory mechanism to overcome hyperactivity. However, GlyRs may be ineffective under normal conditions (Figure $1 \mathrm{Bb}$ and $\mathrm{c}$ ). Consistent with this notion, a low concentration of glycine, which failed to affect E-S coupling in native slices
(Figure 2d), became effective in GlyT1 antagonist-treated slices (Figure 3e). Taken together, our results indicate an essential role of GlyTs in tuning tonic activation of GlyRs in the hippocampus.

\section{Is Glycine a Gliotransmitter?}

The effect of GlyT1 but not GlyT2 antagonists on E-S coupling suggests the involvement of glia in this process, since GlyT1 is located extensively on glia (Gomeza et al, 2003). GlyT1 blockade increases the extracellular concentration of glycine (Martina et al, 2004), which not only facilitated NMDAR-mediated responses (Figure 4), but also activated GlyRs to induce tonic current (Figure 5) and E-S depression (Figure 3) in hippocampal CA1 area. However, since no glycinergic neurotransmission has been found in the hippocampus (Mody et al, 1994), from where was this amino acid released?

FAC suppresses glial activity as well as the function of glial transporters (Swanson and Graham, 1994; Fonnum et al, 1997). In our experiments, the GlyT1 antagonistssarcosine or NFPS failed to affect E-S coupling after FAC treatment (Figure 6), implicating a role of glia in this process. However, subsequent application of STN had no effect on E-S coupling, implying that glia is also essential for the release of glycine. Glia has been shown to contain $\sim 2 \mathrm{mM}$ glycine (Berger et al, 1977), which enables glia to participate in the control of glycine concentration. Furthermore, two-thirds of the axon-dendritic spines in CA1 region are associated with astrocytic processes (Ventura and Harris, 1999), suggesting a wide distribution and close colocalization of glial cells with neurons. In fact, potassium can stimulate the spontaneous release of glycine from astrocytes through a $\mathrm{Ca}^{2+}$-independent mechanism (Holopainen and Kontro, 1989). Bergmann glial GlyT1 can mediate glycine efflux at or more depolarized than $-50 \mathrm{mV}$ (Huang et al, 2004). Furthermore, glia can be triggered to release 'gliotransmitters', such as ATP, glutamate (Bezzi and Volterra, 2001), and D-serine (Mothet et al, 2005), through a $\mathrm{Ca}^{2+}$-dependent and a soluble $\mathrm{N}$ ethylmaleimide-sensitive factor attachment protein receptor (SNARE) protein-dependent mechanism. All these previous observations point to a possibility that glia may provide glycine for regulating neuronal functions. No matter whether glia is the source of glycine release or not, the 
involvement of glial GlyT1 in E-S coupling and LTP suggests a critical role of glia in stabilizing network stability, based on the modulatory effect of extracellular glycine concentration by GlyT1.

\section{Functional Implications of Glycine Accumulation}

Our electrophysiological data obtained in brain slices from young rats (14- to 17-day old) revealed a tonic inhibitory role of hippocampal GlyRs. However, it is important to know whether this GlyR-mediated tonic inhibition occurs in the brain at different levels of maturity. In adult rats we further found that endogenous accumulation of glycine by inhibiting GlyT1 reduced PTZ-induced seizures (Figure 7), consistent with what the slice data predict. In hippocampus, the expression of GlyR $\alpha 2$ subunit, which mediates the tonic inhibition, is abundant in the embryonic state and decreases during the first postnatal week, then reaches the adult level 2 weeks after birth (Malosio et al, 1991). Moreover, the expression of $\mathrm{K}^{+} / \mathrm{Cl}^{-}$transporter $\mathrm{KCC} 2$, which determines the $\mathrm{Cl}^{-}$transmembrane gradient, reaches the level in adult neurons and GlyRs become inhibitory in the first 2 postnatal weeks (Rivera et al, 1999). Thus, it is very likely that, from the postnatal 2 weeks, the predominant role of GlyRs in hippocampus is inhibitory rather than excitatory. Indeed, it has been reported that in several animal models of epilepsy, exogenous application of glycine can depress seizure activity in the hippocampus (Kirchner et al, 2003; Seiler and Sarhan, 1984), confirming an inhibitory influence of glycine on neuronal excitability.

Although GlyRs may not be activated under normal conditions, these receptors could be activated by increased extracellular glycine concentration when GlyTs are downregulated or even reversed under specific pathological conditions, such as ischemia (Huang et al, 2004; Baker et al, 1991). Certain factors can suppress the function of GlyT1, including $\mathrm{Zn}^{2+}$ (Ju et al, 2004) and protons (Aubrey et al, 2000), both of which are stored in transmitter vesicles and transient changes in extracellular $\mathrm{pH}$ or $\mathrm{Zn}^{2+}$ occur during synaptic transmission (Qian and Noebels, 2005; Krishtal et al, 1987). Also, the rate of glycine reuptake by GlyT1 can be downregulated by intracellular factors such as arachidonic acid (Pearlman et al, 2003; Zafra et al, 1990), protein kinase C activation (Sato et al, 1995) or $\mathrm{Ca}^{2+}$ / calmodulin-dependent enzymes (Lopez-Colome and Gadea, 1999). In addition, the intracellular membrane trafficking of GlyT1 can be regulated by the SNARE protein syntaxin-1A (an isoform of syntaxin 1), which decreases the number of GlyT1 proteins on the plasma membrane (Geerlings et al, 2000). Accordingly, the function of GlyT1 is effectively regulated and thus the concentration of extracellular glycine is tightly controlled. Furthermore, the sensitivity of GlyRs, which mainly depends on the $\alpha$-subunit present, may also be upregulated by expression of subunit splice variants with high agonist sensitivity (Miller et al, 2004) or by RNA editing to produce a high agonist potency receptor isoform (Meier et al, 2005). Under the latter conditions, the GlyRs could be activated even if the concentration of glycine is not elevated. Therefore, when GlyT1 is downregulated or the agonist potency of GlyR is upregulated, a homeostatic mechanism to overcome hyperactivity operates by E-S depression through tonic activation of GlyRs. Taken together, our findings indicate that a GlyR-mediated tonic current maintains an inhibitory tone and contributes to E-S coupling as well as network stability in hippocampus, and that glial GlyT1 plays a critical role in this process. Thus GlyT1 inhibitors and other drugs raising extracellular glycine levels as well as GlyR enhancers may be effective for treatment of epilepsy and other brain disorders associated with hyper-excitability.

\section{ACKNOWLEDGEMENTS}

This study was supported by the National Natural Science Foundation of China (No. 30621062), the National Basic Research Program of China (No. 2006CB500803) and the Knowledge Innovation Project from the Chinese Academy of Sciences (KSCX2-YW-R-35). We thank Dr Iain Bruce (Hong Kong University, Hong Kong) for proofreading the manuscript.

\section{COMPETING INTEREST STATEMENT}

The authors declare that they have no competing financial interests.

\section{REFERENCES}

Aubrey KR, Mitrovic AD, Vandenberg RJ (2000). Molecular basis for proton regulation of glycine transport by glycine transporter subtype 1b. Mol Pharmacol 58: 129-135.

Baker AJ, Zornow MH, Scheller MS, Yaksh TL, Skilling SR, Smullin DH et al (1991). Changes in extracellular concentrations of glutamate, aspartate, glycine, dopamine, serotonin, and dopamine metabolites after transient global ischemia in the rabbit brain. J Neurochem 57: 1370-1379.

Becker CM, Betz H, Schroder H (1993). Expression of inhibitory glycine receptors in postnatal rat cerebral-cortex. Brain Res 606: 220-226.

Berger SJ, Carter JC, Lowry OH (1977). The distribution of glycine, GABA, glutamate and aspartate in rabbit spinal cord, cerebellum and hippocampus. J Neurochem 28: 149-158.

Bezzi P, Volterra A (2001). A neuron-glia signalling network in the active brain. Curr Opin Neurobiol 11: 387-394.

Bliss TV, Lomo T (1973). Long-lasting potentiation of synaptic transmission in the dentate area of the anaesthetized rabbit following stimulation of the perforant path. J Physiol 232: 331-356.

Bradaia A, Schlichter R, Trouslard J (2004). Role of glial and neuronal glycine transporters in the control of glycinergic and glutamatergic synaptic transmission in lamina $\mathrm{X}$ of the rat spinal cord. J Physiol 559: 169-186.

Chattipakorn SC, McMahon LL (2002). Pharmacological characterization of glycine-gated chloride currents recorded in rat hippocampal slices. J Neurophysiol 87: 1515-1525.

Chattipakorn SC, McMahon LL (2003). Strychnine-sensitive glycine receptors depress hyperexcitability in rat dentate gyrus. J Neurophysiol 89: 1339-1342.

Chavez-Noriega LE, Bliss TV, Halliwell JV (1989). The EPSP-spike (E-S) component of long-term potentiation in the rat hippocampal slice is modulated by GABAergic but not cholinergic mechanisms. Neurosci Lett 104: 58-64.

Chen L, Muhlhauser M, Yang CR (2003). Glycine tranporter-1 blockade potentiates NMDA-mediated responses in rat prefrontal cortical neurons in vitro and in vivo. J Neurophysiol 89: 691-703. 
Fonnum F, Johnsen A, Hassel B (1997). Use of fluorocitrate and fluoroacetate in the study of brain metabolism. Glia 21: 106-113. Geerlings A, Lopez-Corcuera B, Aragon C (2000). Characterization of the interactions between the glycine transporters GLYT1 and GLYT2 and the SNARE protein syntaxin 1A. FEBS Lett 470: $51-54$.

Gomeza J, Ohno K, Betz H (2003). Glycine transporter isoforms in the mammalian central nervous system: structures, functions and therapeutic promises. Curr Opin Drug Discov Devel 6: 675-682.

Holopainen I, Kontro P (1989). Uptake and release of glycine in cerebellar granule cells and astrocytes in primary culture: potassium-stimulated release from granule cells is calciumdependent. J Neurosci Res 24: 374-383.

Huang H, Barakat L, Wang D, Bordey A (2004). Bergmann glial GlyT1 mediates glycine uptake and release in mouse cerebellar slices. J Physiol 560: 721-736.

$\mathrm{Ju}$ P, Aubrey KR, Vandenberg RJ (2004). $\mathrm{Zn}^{2+}$ inhibits glycine transport by glycine transporter subtype 1b. J Biol Chem 279: 22983-22991.

Jursky F, Nelson N (1995). Localization of glycine neurotransmitter transporter (GLYT2) reveals correlation with the distribution of glycine receptor. J Neurochem 64: 1026-1033.

Kinney GG, Sur C, Burno M, Mallorga PJ, Williams JB, Figueroa DJ et al (2003). The glycine transporter type 1 inhibitor $N$-[3-( $4^{\prime}-$ fluorophenyl)-3-( $4^{\prime}$-phenylphenoxy)propyl] sarcosine potentiates NMDA receptor-mediated responses in vivo and produces an antipsychotic profile in rodent behavior. J Neurosci 23: 7586-7591.

Kirchner A, Breustedt J, Rosche B, Heinemann UF, Schmieden V (2003). Effects of taurine and glycine on epileptiform activity induced by removal of $\mathrm{Mg}^{2+}$ in combined rat entorhinal cortexhippocampal slices. Epilepsia 44: 1145-1152.

Krishtal OA, Osipchuk YV, Shelest TN, Smirnoff SV (1987). Rapid extracellular $\mathrm{pH}$ transients related to synaptic transmission in rat hippocampal slices. Brain Res 436: 352-356.

Legendre P (2001). The glycinergic inhibitory synapse. Cell Mol Life Sci 58: 760-793.

Li Y, Wu LJ, Legendre P, Xu TL (2003). Asymmetric crossinhibition between $\mathrm{GABA}_{\mathrm{A}}$ and glycine receptors in rat spinal dorsal horn neurons. J Biol Chem 278: 38637-38645.

Li Y, Xu TL (2002). State-dependent cross-inhibition between anionic GABA(A) and glycine ionotropic receptors in rat hippocampal CA1 neurons. Neuroreport 13: 223-226.

Lim R, Hoang PD, Berger AJ (2004). Blockade of glycine transporter-1 (GLYT-1) potentiates NMDA-receptor mediated synaptic transmission in hypoglossal motorneurons. J Neurophysiol 92: 2530-2537.

Lopez-Colome AM, Gadea A (1999). Regulation of glycine transport in cultured Muller cells by $\mathrm{Ca}^{2+} /$ calmodulin-dependent enzymes. Ann NY Acad Sci 868: 685-688.

Lu YM, Mansuy IM, Kandel ER, Roder J (2000). Calcineurinmediated LTD of GABAergic inhibition underlies the increased excitability of CA1 neurons associated with LTP. Neuron 26: 197-205.

Malosio ML, Marqueze-Pouey B, Kuhse J, Betz H (1991). Widespread expression of glycine receptor subunit mRNAs in the adult and developing rat brain. EMBO J 10: 2401-2409.

Martina M, Gorfinkel Y, Halman S, Lowe JA, Periyalwar P, Schmidt CJ et al (2004). Glycine transporter type 1 blockade changes NMDA receptor-mediated responses and LTP in hippocampal CA1 pyramidal cells by altering extracellular glycine levels. J Physiol 557: 489-500.

Meier JC, Henneberger C, Melnick I, Racca C, Harvey RJ, Heinemann $U$ et al (2005). RNA editing produces glycine receptor alpha3(P185L), resulting in high agonist potency. Nat Neurosci 8: 736-744.

Miller PS, Harvey RJ, Smart TG (2004). Differential agonist sensitivity of glycine receptor alpha2 subunit splice variants. Br J Pharmacol 143: 19-26.
Mody I, De Koninck Y, Otis TS, Soltesz I (1994). Bridging the cleft at GABA synapses in the brain. Trends Neurosci 17: 517-525.

Mori M, Gahwiler BH, Gerber U (2002). Beta-alanine and taurine as endogenous agonists at glycine receptors in rat hippocampus in vitro. J Physiol 539: 191-200.

Mothet JP, Pollegioni L, Ouanounou G, Martineau M, Fossier P, Baux G (2005). Glutamate receptor activation triggers a calciumdependent and SNARE protein-dependent release of the gliotransmitter D-serine. Proc Natl Acad Sci USA 102: 5606-5611.

Nong Y, Huang YQ, Ju W, Kalia LV, Ahmadian G, Wang YT et al (2003). Glycine binding primes NMDA receptor internalization. Nature 422: 302-307.

Pearlman RJ, Aubrey KR, Vandenberg RJ (2003). Arachidonic acid and anandamide have opposite modulatory actions at the glycine transporter, GLYT1a. J Neurochem 84: 592-601.

Psarropoulou C, Matsokis N, Angelatou F, Kostopoulos G (1994). Pentylenetetrazol-induced seizures decrease gamma-aminobutyric acid-mediated recurrent inhibition and enhance adenosine-mediated depression. Epilepsia 35: 12-19.

Qian J, Noebels JL (2005). Visualization of transmitter release with zinc fluorescence detection at the mouse hippocampal mossy fibre synapse. J Physiol 566: 747-758.

Rivera C, Voipio J, Payne JA, Ruusuvuori E, Lahtinen H, Lamsa K et al (1999). The $\mathrm{K}^{+} / \mathrm{Cl}^{-}$co-transporter $\mathrm{KCC} 2$ renders GABA hyperpolarizing during neuronal maturation. Nature 397: 251-255.

Sato K, Adams R, Betz H, Schloss P (1995). Modulation of a recombinant glycine transporter (GLYT1b) by activation of protein kinase C. J Neurochem 65: 1967-1973.

Seiler N, Sarhan S (1984). Synergistic anticonvulsant effects of GABA-T inhibitors and glycine. Naunyn Schmiedebergs Arch Pharmacol 326: 49-57.

Shleper M, Kartvelishvily E, Wolosker H (2005). D-serine is the dominant endogenous coagonist for NMDA receptor neurotoxicity in organotypic hippocampal slices. J Neurosci 25: 9413-9417.

Smith KE, Borden LA, Hartig PR, Branchek T, Weinshank RL (1992). Cloning and expression of a glycine transporter reveal colocalization with NMDA receptors. Neuron 8: 927-935.

Staff NP, Spruston N (2003). Intracellular correlate of EPSP-spike potentiation in CA1 pyramidal neurons is controlled by GABAergic modulation. Hippocampus 13: 801-805.

Swanson RA, Graham SH (1994). Fluorocitrate and fluoroacetate effects on astrocyte metabolism in vitro. Brain Res 664: 94-100.

Thio LL, Shanmugam A, Isenberg K, Yamada K (2003). Benzodiazepines block alpha2-containing inhibitory glycine receptors in embryonic mouse hippocampal neurons. J Neurophysiol 90: 89-99.

Thomson AM, Walker VE, Flynn DM (1989). Glycine enhances NMDA-receptor mediated synaptic potentials in neocortical slices. Nature 338: 422-424.

Turrigiano GG, Nelson SB (2004). Homeostatic plasticity in the developing nervous system. Nat Rev Neurosci 5: 97-107.

Ventura R, Harris KM (1999). Three-dimensional relationships between hippocampal synapses and astrocytes. J Neurosci 19: 6897-6906.

$\mathrm{Wu} \mathrm{ZY}, \mathrm{Xu}$ TL (2003). Taurine-evoked chloride current and its potentiation by intracellular $\mathrm{Ca}^{2+}$ in immature rat hippocampal CA1 neurons. Amino Acids 24: 155-161.

Yoon KW, Wotring VE, Fuse T (1998). Multiple picrotoxinin effect on glycine channels in rat hippocampal neurons. Neuroscience 87: $807-815$.

Zafra F, Alcantara R, Gomeza J, Aragon C, Gimenez C (1990). Arachidonic acid inhibits glycine transport in cultured glial cells. Biochem J 271: 237-242.

Zafra F, Aragon C, Olivares L, Danbolt NC, Gimenez C, StormMathisen J (1995). Glycine transporters are differentially expressed among CNS cells. J Neurosci 15: 3952-3969. 